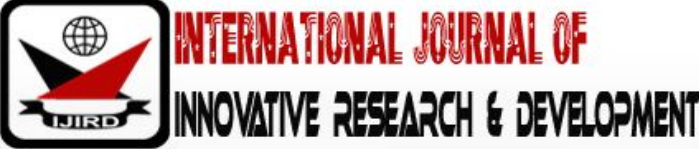

ISSN 2278 - 0211 (Online)

\section{The Convergence of Radio and Mobile Phones as Catalysts for Agricultural Development in Rural Areas}

\author{
Igwebuike Obiora Chinweike \\ Lecturer, department of Mass Communication, Institute of Management and Technology, \\ Enugu State, Nigeria
}

\begin{abstract}
:
This seminar paper x-rayed the convergence of radio and mobile phones as propellers of agricultural development in rural areas. Most agricultural activities are performed in the rural areas and nations of the world depend on agriculture for their food supply. It now beholds on any government to develop such areas. Sources for this work were majorly secondary. This paper adopted mediamorphosis theory which states that communication media transform as a result of perceived needs, political pressure or technological innovations. This theory was propounded by Roger Fidler. Findings revealed that the convergence of radio and mobile phones have really helped farmers to improve their outputs as they get educated on global agricultural best practices on radio and also contribute on such programs with their mobile phones. However, they experience a challenge of language barrier as most programs are done in language they are not familiar with. Based on this, the paper recommends that community radios be established in communities to bridge the gap of language barrier.
\end{abstract}

Keywords: Convergence, mobile phone, radio and rural development

\section{Introduction}

Convergence by way of definition is the coming together of two or more things. In this context, it is the coming together of radio and mobile phones for the purposes of propelling agricultural development.

Over two billion people live in rural areas of developing countries. In Africa, most farmers reside in rural areas. In these rural areas one finds that there is a direct relationship between agricultural and rural development. This comes about by the fact that most people in rural areas depend on agriculture for their livelihood. Food is grown there to feed the whole nation and droughts, diseases and infestations to crops are first felt there. Even research meant for better farming practices is tested there. Therefore, there is the need to keep the communities informed of what is happening in and around them in order for them to adapt to varying situations. Blait (1996) pointed out that the least expensive input for improved rural agricultural development is adequate access to knowledge and information in areas of new agricultural technologies, early warning systems (drought, pests, diseases etc.), improved seedlings, fertilizer, credit, market prices etc. When the rural farmers lack access to knowledge and information that would help them achieve maximum agricultural yield, they are not only grope in the dark but are driven to the urban centers in search of formal employment, as the only option for survival (Munyua, 2000).

The radio has become a valuable medium of communication and dissemination of information, as well as for training and education for broad segments of rural communities (Zijp, 2003). The radio is considered a veritable tool for this because it is the only medium of mass communication that the rural population is very familiar, a radio set is cheap to obtain and is widely owned in the rural areas. Radio's power contributes to mass education because it is easier to attend to than print, and it is more accessible. Listening is easier than reading, and if people of low cultural level are interested in serious subjects, then radio is a more effective way of communication than print (Lazarsfeld,1940).

On the other hand, there has been a rapid growth of mobile phone networks in developing countries. Currently mobile telephony is the predominant mode of communication. Mobile phones are widely recognized as a potentially transformative technology platform for developing nations. Mobile phones are transforming the lives of many users in developing countries and are widely recognized as an important current and future technology platform for developing nations (Lehr, 2007). Mobile phones are considered important for development because they offer benefits such as mobility and security to owners (Donner, 2006).

\subsection{Statement of the Problem}

Information and knowledge is the power to change any society. Most agricultural activities are carried out in the rural areas, it beholds on any government to provide information that will propel development in these areas. Since the 
convergence of radio and mobile phones, do farmers have access to information that will improve their yields? Do they also participate in programs targeted to them? Are there any challenges they face? This paper seeks to answer these questions.

\subsection{Objectives of the Study}

The general objective of the study is on the community radio as a vehicle for agricultural development in rural areas. Therefore, the objectives of this study are;

- To identify the extent of agricultural improvement in rural areas.

- To examine how information has helped in the famers' productivity.

\section{Literature Review}

Relevant literatures were reviewed. They are mainly from secondary sources.Nations around the world depend on agriculture for their food supply. It is however appalling that agriculture which is predominantly practiced in rural areas has little or no development. Rural farmers account for the greater part of the population of any developing country such as Nigeria. Governments of developing countries have a major responsibility of ensuring that there is adequate rural development in their various communities and local governments which would lead to effective and efficient agricultural systems that will not only supply food and animal protein but also foster the utilization of natural resources in a sustainable manner (CGIAR, 1995). When the rural farmers lack access to knowledge and information that would help them achieve maximum agricultural yield, they are not only grope in the dark but are driven to the urban centres in search of formal employment, as the only option for survival (Munyua, 2000). As Blait (1996) pointed out that the least expensive input for improved rural agricultural development is adequate access to knowledge and information in areas of new agricultural technologies, early warning systems (drought, pests, diseases etc.), improved seedlings, fertilizer, credit, market prices etc. There have been short-comings of traditional print and library-based methods (Van and Fortier, 2000) of providing such agricultural information to rural farmers who are generally illiterate and relatively remote from formal sources of information (e.g. extension stations, libraries). Aina (2007) argues that farmers would benefit from global information, if information centres, are cited in rural areas complete with all information and communication gadgets.

Where rural farmers are not faced with constraints in accessing agricultural information, traditional media such as rural radio, has been used in delivering agricultural messages to rural farmers (Munyua, 2000).

Information and knowledge are very vital in agricultural development of any community and where they are poorly disseminated as a result of certain constraints, the community's agricultural development becomes highly impeded.

\subsection{Radio Defined}

Radio is an avenue for participatory communication and a tool relevant in both economic and social development (Kumar, 2004). Radio in this regard provides a set of participatory communication techniques that support agricultural development efforts by using local languages to communicate directly with farmers and listeners' groups. Radio is used extensively as a communication medium in developing countries to support educational programmes in teaching, health, literacy training, nutrition education, and the promotion of changes in farming practices to improve agricultural production (Nwaerondu \& Thompson, 1987). Furthermore, radio as a communication medium does not require literacy. The increasing shift to community radio program production and broadcasting is also removing barriers of language and dialect. As a result, radio has become a valuable medium of communication and dissemination of information, as well as for training and education for broad segments of rural communities (Zijp, 2003). Many experts identify radio as the most appropriate medium for rural emancipation programmes (Okwu, Kuku \& Aba, 2007). The advantages are that: It overcomes distance, and thus has immediate effect; It is the only medium of mass communication that the rural population is very familiar with because a radio set is cheap to obtain and is widely owned in the rural areas. This is made possible by the advent of the battery-operated transistorized sets and the invention of wind-up radio (Kuponiyi, 2000); Radio's power contributes to mass education because it is easier to attend to than print, and it is more accessible. Listening is easier than reading, and if people of low cultural level are interested in serious subjects, then radio is a more effective way of communication than print (Lazarsfeld, 1940).

\subsection{The Importance of Radio in Communicating Agricultural Information}

Information is important for farmers to maintain livelihoods and to gain a competitive edge in a rapidly changing economic and production environment where traditional farming methods might be ineffective to meet new demands (Morton $\&$ Matthewman, 1996). Unfortunately, most African countries have not devoted enough attention to provide their citizens with access to information, especially in rural areas where $70-80 \%$ of the African population lives (Youdeowei, Diallo \& Spiff, 1996). Agricultural extension represents a mechanism by which information about new technologies, better farming practices, and better management can be transmitted to farmers. Reisenberg \& Gor (1989) stated that the extension services are experiencing a declining impact and more emphasis is being placed on the use of mass media for agricultural information transfer. Zijp (2003) observed that face-to-face communication between extension agents and farmers, while crucial, cannot fulfill all of the farmers' information needs. Extension agents are too few in number and, particularly in emergency situations like those related to weather or a pest infestation.

As a result, radio has been recognized as a highly cost-effective technology to convey information, training, and technology in rural areas. 
Elsewhere in the world there has been a notable increase in the use of radio since the

1980s. The successes of radio have been observed in Botswana for civics education, in

India for rural development, in Nigeria's agricultural sector, in the Benin Republic to educate rural peasant farmers (Nwaerondu \& Thompson, 1987), and in Malawi to communicate agricultural and rural development information (Manyozo, 2005)

\subsection{Mobile Phone and Its Uses}

A mobile phone (also known as a cellular phone, cell phone, hand phone, or simply a phone) is a phone that can make and receive telephone calls over a radio link while moving around a wide geographic area. It does so by connecting to a cellular network provided by a mobile phone operator, allowing access to the public telephone network. By contrast, a cordless telephone is used only within the short range of a single, private base station.

In addition to telephony, modern mobile phones also support a wide variety of other services such as text messaging, MMS, email, Internet access, short-range wireless communications (infrared, Bluetooth), business applications, gaming, and photography. Mobile phones that offer these and more general computing capabilities are referred to as smartphones.

The livelihoods of millions in the developing world depend heavily on agriculture and small businesses. The agricultural sector as the mainstay of most African economies accounts for about $60 \%$ of the total labourforce, $20 \%$ of the total exports and $17 \%$ of the GDP and provide livelihoods to over 70\% of the population (ACACIA,2006). Agricultural production for local consumption and export in East Africa plays a critical role in national economies, making up 40\% of the sub-region's Gross Domestic Product (GDP). It employs nearly $80 \%$ of the people who are mostly small-scale farmers and depend on agriculture for their livelihoods. These smallholder farmers need to access the information about new technologies before they can consider adopting them and thus look up to research and extension agents as sources of new technologies. However, the traditional approach of providing agricultural information through extension services is overstretched and under-resourced. It is in working with and improving these information and communication systems that ICTs can be used to enhance the delivery of these services (ACACIA, 2006).

Agricultural information is a key component in improving small-scale agricultural production and linking increased production to remunerative markets, thus leading to improved rural livelihoods, food security and national economies. Improvement of agricultural productivity will be realised when farmers are linked to market information. However, one major problem in many rural regions is that farmers and small entrepreneurs generally have no way of knowing prices before they travel to the market due to poor communication facilities. They often have to rely on middlemen who take advantage of this ignorance. In particular, small-scale farmers have poor market infrastructure, inadequate marketing experience, and agricultural inputs (Munyua, 2007). Accurate and timely market information, particularly of perishable items, can significantly reduce transaction and travel costs. There have been quite a few studies that explored how mobile phones impact livelihoods of farmers (Rashid and Elder, 2009). Correspondingly, a positive view that mobile phones offer good value for money appears to support the uptake of mobile phone applications. The importance of knowledge and information sharing in research for development (R4D) settings has been firmly established through research. Access to appropriate information and knowledge is an overriding factor for successful natural resource management (NRM) planning, implementation and evaluation processes, and it is known to be one of the most determinants of agricultural productivity. Knowledge and innovation are now widely regarded as key drivers of economic growth and it is clear that information and communication technologies (ICTs) are deeply implicated in knowledge flow and innovation (Verlaeten, 2002).

\subsection{Concept of Rural Development}

Development is complex and multidimensional phenomena which mean different things to different people (Todaro, 2000). According to World Bank (2005), development is about change and change cannot occur without communication. Nyerere (1968) and Sen (1981) sum up that the purpose of development should be human empowerment, human dignity, freedom and commitment to quality life. Rural development, therefore is a holistic approach concerned with improvement of the living standard of low-income population living in rural areas. It takes holistic approach because rural dwellers engage in various sectors to earn their livelihood.

Rural development can be distinguished from agricultural development which it entails and transcends. In essence Rural Development may imply a broad-based re-organization and mobilization of rural masses in order to enhance their capacity to cope effectively with the daily task of their lives and with changes consequent upon this. According to the World Bank Rural Development must be clearly designed to increase production. It recognizes that improved food supplies and nutrition, together with basic services, such as health and education, not only directly improve the physical well-being and quality of life of the rural poor but can also indirectly enhance their productivity and their ability to contribute to the national economy.

\subsection{Theoretical Framework}

Mediamorphosis theory by Roger Fidler (1997) was found most applicable to this paper and therefore was adopted. According to Fidler (1997) Mediamorphosis is the transformation of communication media, usually brought about by the complex interplay of perceived needs, competitive and political pressures, and social and technological innovations. All forms of communication are tightly woven into the fabric of the human communication system and cannot exist independently from 
one another in our culture. As each new form emerges and develops, it influences, over time and to varying degrees, the development of every other existing form. Co evolution and co-existence, have been the norm rather than replacement. Existing forms of media evolve when a new form enters, and each form is operating in an ecosystem where its evolution is dependent on the evolution of those around it.

Before now the radio has been used as one of the forms of mass communication in informing and educating the people. But, these days one can easily call in into a program and make contributions and ask questions. This is known as the convergence of radio and telephone.

\section{Conclusion}

The success of agricultural development programs in rural areas largely depends on the nature and extent of use of the media in mobilization of farmers for development. The planners in rural communities realize that the development of agriculture could be hastened with the effective use of mass media.

Radio, a sub sector of the mass media, has been acclaimed to be the most effective and valuable medium of the mass media for disseminating information to the rural populace. Findings reveal that radio is effective in improving the sharing of agricultural information by remote rural farming communities. Radio in this regard provides a set of participatory communication techniques that support agricultural development efforts by using local languages to communicate directly with farmers. This bridge the gap caused by mainstream reporting. Mobile phones also have helped farmers in gaining access to information that could transform their farming experiences. Instant updates on weather, crop prices, inputs availability, market and financial information can considerably improve their productivity and negotiating positions. Mobile phones have enabled farmers to become active participants to agricultural programs targeted to them through the radio. However, the challenge the farmers have is that of language as most agricultural programs are often disseminated with language they are not familiar with, hence, the need to solve the language barrier to give rise to agricultural development.

\subsection{Recommendations}

Based on the findings, the study recommends that:

- Government should establish community radios otherwise known as rural radios one that is specifically set up to cater to the needs of communities to bridge the language barrier, as the study shows that radio stations are alienated from the community and from listeners. This will also create jobs.

- Development planning and practice in Nigeria should be integrated, and there is a need to ensure that the tasks that radio is encouraging people to perform in its jingles and programmes are feasibly supported by existing infrastructure;

- Government to support private stations in order for them to more effectively participate in development communication;

- Nigerian communication schools and colleges should review their curricula to include topics on public journalism, also known as civic or citizen journalism. It says that public journalism seeks to put the citizens at the centre of news and reports. If radio is to perform public service and engage development effectively, we need producers and presenters who are citizen-conscious and citizen-loyal. Presenters who can move into rural areas should rural radios be established.

\section{References}

i. Annual Meeting of the American Political Science Association, Boston Marriott Copley Place, Sheraton Boston and Hynes Convention Center, Boston, Massachusetts, USA, available at: http:/ / www.allacademic.com/ meta/ p66274 index.html

i. Figueroa, M. E., Kincaid, D. L., Rani, M. and Lewis, G. (2002). Communication for social change: an integrated model for measuring the process and its outcomes The Communication for Social Change Working Paper Series No. 1. New York: The Rockefeller Foundation.

ii. Gamon, J. A., Bounaga, L. and Miller, W. W. (1992). Identifying information sources and educational methods for soil conservation information used by landowners of highly erodible field.

iii. Hambly, H. (2007). Communicating Agricultural Research in Africa: The New Role of Rural Radio. Available: http:/ / www.comminit.com/ en/ node/ 223240/ 36.

iv. ACACIA (2006): ACACIA Prospectus 2006-2011. http:// www.idrc.ca/ acacia/ ev-113431-201-1-DO_TOPIC.htlm

v. DonnerJ. (2006). The Social and Economic Implications of mobile Telephony in Rwanda: An ownership/ Accesss Typology,Knowledge, Technology and Policy,19,2,17-28.

vi. Lehr,D. (2007). Going Wireless: Dialing for Development (working paper) http://mobileactive.org/ dialingdevelopmentnew-report-mobile-phone-use-base-pyramid

vii. Munyua,H. (2007). ICTs and Small Scale Agriculture in Africa: A Scoping Study: Ottawa:IDRC

viii. Waverman L Meloria M And Fuss,M. (2005). The Impact of Telecoms on Economic growth in Developing Nations. In Africa: The Impact of Mobile Phones. The Vodafone policy paper series,3:10-23. 